\title{
Inland Empire (2006) de David Lynch: Paradigma de intermidialidade no cinema contemporâneo
}

Prof. Dr. Miguel Angel Lomillos, Centro de Ciências Sociais, Saúde e Tecnologia, Universidade Federal do Maranhão, CCSST - UFMA, Imperatriz, MA; E-mail:<lomisi@hotmail.com.br>.

\section{Resumo}

O objetivo deste trabalho é analisar Inland Empire (2006), de David Lynch em função dos processos intermidiáticos e dos processos de significação que a configuram como uma obra síntese tanto do universo lynchiano quanto do assim denominado pós-cinema ou cinema pós-moderno. Essa obra chave de Lynch parece guiar-se, com mais determinação ainda que outros trabalhos autorais e vanguardistas do cinema contemporâneo, pela condição do "entre", das "passagens", da transversalidade de dispositivos, agenciamentos e sistemas simbólicos: no espaço-tempo da diegese (entre a Califórnia e Lodz), nos deslocamentos de identidade da figura feminina, nos registros de imagem e som (épico, teatral, cinematográfico, televisivo, circo, conto, performance, videoarte, etc.).

Palavras-chave: Intermidialidade, cinema de autor, David Lynch, artes, estética, análise fílmica.

Inland Empire (no Brasil, O Império dos Sonhos), o último trabalho cinematográfico de David Lynch até o presente e o primeiro longa-metragem que realiza completamente em vídeo digital, é uma obra complexa que configura uma obra síntese tanto do universo lynchiano quanto do assim denominado póscinema ou cinema pós-moderno.

Inland Empire é "um híbrido entre videoarte, performance e cinema de autor" (Ortiz de Zárate, 2011: 34) O maior controle na produção e a versatilidade do vídeo digital (a pequena e ligeira câmera Sony PD 150) Ihe permitiu a Lynch experimentar nas texturas, na iluminação, na composição de planos, nas qualidades plásticas e musicais da imagem: por exemplo, há imagens com glamour, outras em tom documental, há 
momentos em que investe na deformação do rostos, no intenso contraste entre as áreas de luz e de sombras.

O filme de Lynch pode definir-se como uma "figuração intermedial" (Paech, apud Rajewski: 45) e em função disso, analisarei, primeiro, a configuração da estrutura e das figuras do filme para, finalmente, concluir com os principais processos intermidiáticos de Inland Empire.

Configuração da estrutura e das figuras do filme: metalinguagem, níveis narrativos.

Inland Empire se alimenta do próprio meio cinematográfico. $\mathrm{O}$ filme começa com um feixe de luz sobre um fundo escuro, metáfora do projetor cuja luz faz aparecer o titulo do filme em grandes letras capitais ocupando o espaço completo da tela.

O filme inicia-se mostrando três acontecimentos que perpassam o filme todo:

1-Axxon $\mathbf{N}$ : cifra mágica, ritual de passagem. Este termo é apresentado por um locutor como "o programa de rádio mais longo da história" enquanto as imagens em preto e branco mostram uma agulha passando por um disco de vinil.

2-Lost Girl (a atriz polonesa Karolina Gruszka): encerrada num quarto de hotel, uma garota vê, chorando, a tevê: na tela, há, primeiro, manchas e ruído; depois, algumas imagens em acelerado do próprio filme Inland Empire se fazendo. Seu mundo é do conto (uma espécie de encerro provocado pelo malefício de um monstro mau), mas a TV é aqui condutora das imagens de todos esses mundos paralelos em conexão "catódica".

3-Rabbits: uma família de três coelhos humanos situados em um cenário teatral, geralmente focada num único plano geral contínuo (um pouco como no teatro filmado, mas com risadas e aplausos de um público ausente como no sitcom). Aqui a 
referência é Rabbits, a série de 9 pequenos episódios feita por David Lynch em 2002.

Ainda no início, uma cena em preto e branco dá o tom e o tema do filme em consonância com a situação da Lost Girl e com a peça anunciada pelo locutor radiofônico "Um dia cinzento em um velho hotel...". Com as cabeças apagadas por meio de um simples efeito digital, um homem e uma mulher poloneses, ele no comando, ela completamente desorientada, entram de um escuro corredor a um quarto de hotel, estilo imperial. O homem pede a mulher, prostituta, de tirar a roupa. A mulher carece de memória (não reconhece o corredor nem o quarto, não sabe onde deixou as chaves), parece se sentir culpada por algo que ignora e está com medo. Os homens parecem ter a chave das portas e as mulheres ficam prisioneiras nos quartos (violência doméstica, prostituição, tráfico de brancas, máfias, etc). Como sempre em Lynch, é a pulsação do sinistro (Freud, 1980) ${ }^{1}$, ao mesmo tempo sublimado e "concretizado" (embora em Inland Empire a representação do mal, da perversão e da violência é menos acentuada que nos filmes anteriores do cineasta norteamericano).

Ainda que o cineasta apresente estes vetores já no inicio do filme como exposição das forças ou figuras que interagem em vários níveis e camadas de um universo onírico (há um mundo que se fala polonês, há um mundo que se fala inglês, há um

1 Este texto de Freud, publicado em 1919, desenvolve o célebre termo das Unheimliche, "o que não é familiar, é indomesticado, estranho $e$ inquietante, o que assombra àquele que o experimenta, 0 sinistro. Se elabora tal questão baseado em grande número de exemplos e escritos, se o que interessa é mostrar como a Psicanálise encara e produz a questão da Unheimlichkeit, um escrito, melhor dito, um enredo, roteiro ou argumento é seu fio condutor: o conto ou novela $O$ homem da areia, der Sandmann, escrito por Ernst Theodor Amadeus Hoffmann (1776-1822) e situado entre suas "peças noturnas" (die Nactsücke)" (Katz: 1). O texto de Freud encontra-se no vol. XVII da Trad. Brasileira, Standard Edição Brasileira, Imago. 
"palácio" a que acessamos pela mediação de um Coelho, há o universo do conto com uma "princesa" prisioneira), é sem dúvida o filme dentro do filme o motor da história e do discurso.

A dupla de amantes Nikki / Devon (os atores que interpretam On High in Blue Tomorrows) se sobrepõe a dupla de amantes Sue / Billy (os personagens que interpretam) criando um efeito de mistura e coalescência bem típico das estratégias de miseen-abyme. Em um momento do primeiro ensaio de On High in Blue Tomorrows nos estúdios de Hollywood (concretamente no stage 4) há uma visita inesperada e misteriosa que o interrompe e o diretor Kinsgley (Jeremy Irons) Ihes revela a Nikki Grace (Laura Dern) e Devon Side (Justin Theroux) que o filme se trata de uma espécie de remake de uma produção alemã intitulada "47" ("Für Seven"), baseada em um conto cigano do folclore polonês. Trata-se de um filme amaldiçoado já que nunca foi terminado por causa da misteriosa morte dos dois protagonistas.

As relações entre filme 1 e filme 2 vão se tornando cada vez mais emaranhadas até o momento em que Nikki "atravessa o espelho" e é jogada no interior do universo sinistro e perturbador da ficção polonesa (a casa de Smithy, que transmuta de cenário do stage 4 em "casa real" faz a mágica transição). A partir desse momento, não se sabe mais o que é filme 1 e o que é filme 2. Esta cena fundamental do filme o divide em duas partes (Califórnia, Lodz - no desfecho a ação retorna a Califórnia) e o próprio filme o pontua retomando as imagens iniciais em preto e branco da agulha riscando o disco do gramofone (e sobrepondo o rosto de Nikki ao rosto da Lost Girl).

Nessa segunda parte 'polonesa' não há cenas no set de filmagem, aquilo que marca o desenrolar de Inland Empire ambientado na Califórnia (poderíamos dizer que elas são elididas e apenas retornarão no desfecho de Los Angeles para 
dar uma "outra volta de parafuso" à história de Nikki) ${ }^{2}$. A parte ambientada na Polônia ocupa todo 0 universo da representação e cria um universo autônomo (onírico) que admite todas as conexões possíveis de personagens, tempos e espaços. Uma vez que Inland Empire perde os pontos de apoio entre filme 1 e 2, ele perde igualmente qualquer ponto de referência e investe para valer na desestruturação e descentramento de perspectivas (agora, a questão mais interessante que subjaz no filme é a seguinte: que rostos ou camadas há por trás da Nikki/Sue polonesa?).

A protagonista NikkilSue já não é a personagem chique e elegante de On High in Blue Tomorrows (ela e Devon\Billy parecem saídos do mundo glamouroso de $O$ grande Gatsby de Fitzgerald), mas uma mulher de classe baixa, despenteada, infeliz, casada com um homem estranho que a abandona para fugir com uma trupe de circo; enfim, uma mulher desiludida nas relações com os homens marcadas quase sempre pelos acessos de violência como the conta ao Interrogador ou Confessor (Laura Dern pontua, em inglês, esta parte com sotaque sulino e recheado de palavrões, diferente do refinado sotaque do norte na parte de Califórnia).

Nessa segunda parte 0 filme investe maciçamente na proliferação de identidades abertas e múltiplas, especialmente nas personagens principais (Nikki, seu marido Król, Lost Girl e Crimp), e isto é possibilitado pelo fato de que há, pelo menos, dois tempos no passado: há uma velha Polônia (vemos carroças de cavalos e carros dos anos 1950) e há uma nova Polônia que poderia ser "contemporânea" ou de algumas décadas atrás.

2 Inland Empire pode ser visto como uma crítica a Hollywood que coloca ora banalidade, ora glamour, na representação das outras culturas e línguas. Quando a história retorna a Califórnia, com a Sue menos glamourosa, há um forte investimento em retratar em tom documental as ruas de Los Angeles, incluída o Walk of Fame, e inclusive com personagens "sem teto". 
Para melhor entender as estranhas leis e forças que agem no críptico e inextricável universo ficcional da parte polonesa (onde, entre outras coisas, acontece uma sequência de assassinatos), convém descrever as figuras do filme -dado que há hierarquias nas figuras agindo nos diversos níveis diegéticonarrativos- em termos mito-simbólicos de deuses, semideuses e humanos.

O grupo dos deuses estaria composto pelo universo dos coelhos humanos, capazes de abrir e fechar portas, atravessar limiares de mundos diversos, apresentar personagens ou comentar ações dos humanos, com frases aparentemente desconexas, mas que tem tudo a ver com momentos da história. Ao lado deste mundo, ou melhor, um "nível ou grau" abaixo, num espaço figurativizado como "o palácio", estariam Janek e o anjo caído conhecido como Phantom (Fantasma). Janek é o guardião ou intercessor dos coelhos no mundo dos humanos. Já no início do filme, um insistente e nervoso Phantom (o excelente ator polonês Krysztof Majchrzak) pede um "ingresso" ou passagem a esse mundo superior a um irritado Janek (Jan Hencz). Em outro momento, Phantom aparece como Crimp; eles são, em qualquer caso, figurações humanas de um poder maléfico e cruel que os coelhos tentam dissipar agindo por meio dos semideuses e em favor de alguns humanos (especialmente NikkilSue). Na parte polonesa, há a um litígio entre Phantom e o grupo de homens comandado por Janek, que em sessão de vidência articulada "na distância" pelos coelhos (trazendo o espírito de Lost Girl na sessão), tentam destruir o influxo de Crimp sobre Smithy, o marido pobre da Sue polonesa. Finalmente, o judeu K, no papel de Interrogador ou Confessor (num espaço "aberto" pelo coelho, cujo poder é sempre pontuado em fusão de planos) cumpre como Janek o papel de intercessor.

No nível intermédio e intermediário dos semideuses estaria a "bruxa" que visita a casa de Nikki no inicio do filme (a atriz lynchiana Grace Zabriskie) e o bando de prostitutas, 
mediadoras prosaicas, vivificadoras e frívolas que guiam o percurso de NikkilSue na Polônia e finalmente na Walk of Fame de Los Angeles.

$\mathrm{Na}$ esfera dos humanos, as personagens femininas (Nikki, Doris Side, a esposa de Devon -Julia Ormond-, Lost Girl, as duas mulheres "sem teto" de Los Angeles, uma negra, a outra asiática) têm maior capacidade de agir que os homens, ora passivos e fracos (Devon, o diretor Kingsley, seu ajudante Freddy, o negro que acompanha a jovem asiática na cena da morte em Los Angeles), ora violentos e cruéis, baderneiros e truculentos (homens do circo, homens que povoam as histórias em flashback da Sue "polonesa", etc.). No geral, as confusas histórias que povoam o filme pontuam a completa fissura entre homens e mulheres, frisando, em um tom sempre discursivo e performativo-paródico (cinema pós-clássico) em detrimento da ação e da narratividade (cinema clássico), a incapacidade dos homens de responder às demandas do amor feminino.

Há, no entanto, uma figura masculina cujo estatuto ganha certo dom das instâncias superiores: Piotr Król (Peter J. Lucas), o marido de Nikki e suas duas encarnações na Polônia. $\mathrm{Na}$ Califórnia ele é um produtor poderoso, homem observador, reflexivo, dono de certo poder visual na grande mansão e nos estúdios. Nos dois "tempos" da Polônia, ele encarna, por um lado, Smithy, o marido pobre que adere a turma do circo e trabalha para Crimp, sendo o encarregado de cometer 0 assassinato predestinado pela bruxa ("às 9:45 mas será a meia-noite", no entanto tal ação é elidida) e o marido -agora com bigode- no tempo da velha Polônia que será assassinado.

As ambiguidades e contradições que configuram esse magma de "vidas e universos paralelos" são decorrência, entre outros fatores, das múltiplas personalidades e papéis (esposa e marido) encarnadas pelo mesmo corpo da atriz Laura Dern e do ator Peter J. Lucas. Ele pode ser tanto uma entidade com poderes para espreitar a "entrada no espelho" de Nikki, quanto um homem ordinário e fraco que titubeia entre a esposa e os 
homens do circo, entre as forças opostas de Janek e as de Crimp, entre o assassino e o assassinado.

O percurso de NikkilSue, vetor principal do intrincado relato hiper-performativo, se vê sempre sacudido por forças que parecem atuar por cima dela. Daí que a gestualidade de seu rosto seja, maiormente, o pasmo (a atriz americana possui um particular dom para mostrar ilimitados nuances com a boca aberta), a perturbação, o medo, o choro, a irritação, a risada nervosa. Tudo o percurso desta heroína abismada é perpassado por um crescendo de espelhamentos, passagens a um outro limiar ou esfera, sucessão de mises-en-abîme -a (auto)representação, reitero, é trabalhada no tom irônico e autoparódico típico do cinema pós-moderno. Seu percurso não é tanto uma interiorização, ou um descensus ad ínferos (embora tenha que passar por uma morte que, afinal, se revela, num último golpe de magia, uma cena de filmagem de On High in Blue Tomorrows), mas um jogo incessante da irreversibilidade produzida pelas duplicidades e virtualidades do par atriz-papéis (portentoso e camaleônico, o trabalho da atriz norte-americana é um verdadeiro tour de force). Embora trabalhado no universo do conto, não há iniciação no percurso da personagem.

A imagem-cristal, tal como descrita por Deleuze, torna-se ciranda cristalina que nos seduz pela capacidade do cinema de trabalhar no "entre", nas passagens e momentos transversais e condutores de energia. Porém a relação entre a imagem atual e a imagem virtual que não cessa de girar ou mudar nessa categoria bifacial que é a imagem-cristal sofre aqui um colapso ou curto-circuito a partir da segunda parte do filme. Agora já não é um jogo entre o atual e o virtual, o presente e o passado, a percepção e a lembrança, o real e o imaginário, mas virtualidades $1,2,3,4$ da própria imagem virtual, ciranda do virtual que se "atualiza" em ilimitadas virtualizações. Para que exista indiscernibilidade entre a imagem atual e a virtual (o real e o imaginário) deve haver, como aponta Deleuze, distinção 
entre as duas esferas (da mesma forma que a análise dos processos de intermidialidade exige uma distinção de cada mídia $\left.{ }^{3}\right)$.

Quebrada a referência com o real enquanto imagem atual que fixa umas coordenadas na circulação das imagens (o real é agora um magma misturado com o imaginário, um Todo em que pululam os universos paralelos), as duplicidades, projeções e reflexos se encerram no desfile de continuas irreversibilidades e espirais puramente formais que asfixia o extracampo e converte o acaso em mera coincidência plástica ou formal de linhas e movimentos.

O filme se converte em um tapete ou superfície que se alimenta de si próprio: a experiência da temporalidade (da subjetividade, enfim) fica esvaziada e encerrada em uma convergência mágica de pontas que se tocam, todas elas formando parte de uma massa amorfa do Passado. As frases que se repetem como um mantra, "aconteceu alguma coisa ontem, mas é amanhã" ou "olha para mim e me diga se eu te conheci antes", mostram a diegetização dos "universos paralelos" nos diálogos e a redução da temporalidade à palpitação 'misteriosa' de ações pré-destinadas pelas analogias. Sendo que tudo está conectado com tudo, o espaço pode se esticar como chiclete: NikkilSue sai da sua casa na Polônia e chega de carro a seu casarão californiano, entra pela porta de serviço como corresponde agora a sua condição social "inferior", mas o lugar é agora habitado pela família de

3 Considero relevante, a este respeito, ressaltar o paradoxo que levanta F. Jost: «Le paradoxe de cette intermédialité militante, c'est que, en même temps qu'elle va puiser son inspiration en dehors du champ sémiotique propre, elle s'affirme comme une recherche de la spécificité, puisqu'il s'agit, au fond, d'éprouver les limites de chaque art, de chaque pratique, l'une par l'autre» (Jost: 111). 
Devon onde a protagonista terá uma acirrada briga com Doris Side ${ }^{4}$.

Processos intermidiáticos: o mundo do conto e do cinema, o mundo da TV e do cinema.

Há em Inland Empire um enorme plantel de processos e referências intermidiáticos nos registros de imagem e som: épico, teatral, cinematográfico, televisivo, clip (a música Locomotion, entre outras), circo, cabaret, conto maravilhoso, performance, videoarte, pintura (E. Hopper, Francis Bacon), Filosofias Orientais e Transcendental (temporalidade, vidas e universos paralelos, etc).

No universo do conto, além das referências intertextuais a esta forma narrativa tradicional (conto cigano polonês, conto judeu, $\mathrm{O}$ mago de $\mathrm{Oz}$ ), temos de resenhar questões estruturais como a temporalidade do filme e o encerro de Lost Girl. Walter Benjamin, no extraordinário texto "O narrador", nos dá uma apropriada definição da intersecção de conto, performance e relato em Inland Empire: "os personagens dos contos, mais que seres com psicologia e vida interior própria que manifestam reações e sentimentos num percurso temporal, expressam uma condensação energética, como se os fatores individuais e locais perdessem interesse em beneficio do sentido psicológico essencial e único".

Considero que junto com a matriz do conto, as passagens TVCinema são o ponto principal do filme de Lynch. Graças ao poder da montagem "intermedial" das imagens e sons, aquilo que venho descrevendo como o "magma de vidas e universos paralelos" se compendia numa imagem recorrente: o que faz e vê a mulher prisioneira, a Lost Girl na frente do aparelho de TV.

\footnotetext{
${ }^{4}$ Não se trata apenas das questões da verossimilhança e do gênero propostas pelo relato (questões que consegue articular com plausibilidade, por exemplo, o escritor inglês Philip Pullman com suas ficções fantasiosas), mas da mistura espessa entre as falas prosaicas improvisadas e o tom de fantasia.
} 
Tudo está conectado no universo... audiovisual. Ela não é apenas a personagem do conto maravilhoso que será liberada no final graças ao papel derradeiro de uma Nikki Doadora, mas, sobretudo, uma metáfora do filme se fazendo, de ver que é pressentir no universo diegético- o que está acontecendo por sua volta, por volta da história, nesse universo onde tudo parece estar conectado por forças estranhas e invisíveis.

Certamente, a TV é a mídia todo-poderosa que rege (n)o mundo contemporâneo: a "imagem televisual chega em toda parte, numa infinidade de lugares e é recebida com a maior indiferença" (Dubois, 2004). Porém, em Inland Empire, a TV, o dispositivo da imagem vídeo eletrônica opera como verdadeiro condutor de energia, como se a imagem digital do filme que vemos brotasse daí, desse buraco negro que tudo "pode ver".

Logo no início do filme, a Lost Girl, chorando ${ }^{5}$, vê a pequena tela aparecer com manchas (típico sinal de "ruído eletrônico", sem imagem), e depois, em imagens aceleradas, momentos do filme Inland Empire como os Rabbits, a "bruxa" vizinha que visita a casa de Nikki e fora do aparelho de TV, a imagem superposta em efeito digital de um braço que se estende como querendo procurar refugio (parece o braço de uma criança e afinal descobriremos que a liberação da Lost Girl resulta no reencontro com o marido e o filho).

O fato de que não é apenas a imagem, mas o próprio aparelho condutor o que está em pauta, se enfatiza nos planos que mostram a Lost Girl vendo as manchas "sem imagem" da TV com o reflexo alaranjado das lâmpadas. A televisão, no fundo, serve a Lynch para "diegetizar" os recursos deus ex machina e multiplicar o poder da Imagem (e do Conto) em sua capacidade de fascínio e encantamento.

${ }^{5}$ Lembremos que Rebekah Del Rio, uma das vozes femininas de Rabbits, canta a cappella a música de Roy Orbison em espanhol (Llorando, Crying) no Club Silencio em Mulholland Drive (2001). Em um momento da atuação, a cantora desmaia, mas o canto continua. 
A lâmpada, motivo cenográfico, plástico, narrativo e simbólico fundamental na obra de Lynch já desde Eraserhead, tem poderes ainda maiores em Inland Empire. Ela é associada ao poder dos Rabbits e do Phantom (luz vermelha), motivo plástico-lumínico ainda para as transições a outros estados e mundos paralelos.

Em Inland Empire, a imagem televisual não é amnésica, mas uma vasta memória, não é extensiva como a mídia eletrônica, mas intensiva, não atua na Comunicação, mas na Comunhão (estou parafraseando a Dubois, mas invertendo os sentidos).

A TV é a vasta memória desse mundo interconectado. No final do filme, David Lynch mostra todo o poder da imagem vídeo ao aproximar NikkilSue do rádio de ação dela. A morte de Sue em Walk of Fame se revela afinal como a última filmagem de On High in Blue Tomorrows, mas a Nikki que retorna ou "ressuscita" é ao mesmo tempo um ser lúcido e transtornado, uma espécie de mistura de todas as identidades que encarnou. Ainda abismada, ela olha diretamente para a câmera (para nós espectadores), vê no teatro diversos trechos ou imagens do filme que estamos vendo (On High in Blue Tomorrows e Inland Empire), vê a si própria olhando na tela, no teatro vazio (simultaneidade da TV, mas também do cinema) e finalmente, logo que mata ao Phantom ${ }^{6}$, tem acesso ao quarto " 47 " do hotel num in crescendo de imagens simultâneas entre a situação que está acontecendo e sua transmissão na pequena tela do quarto onde fica reclusa a Lost Girl. Obviamente, sem esse recurso "mágico" à simultaneidade de imagens, a cena ficaria sem força, prosaica. A capacidade de vigilância, controle e passagem das máquinas de visão e de escuta já é tema antigo desde os primeiros filmes de Fritz Lang. O cinema digital, após o vídeo, incrementou tal poder. No entanto, Lynch

\footnotetext{
${ }^{6}$ Há um momento aí, sem dúvida uma das imagens mais reveladoras e impactantes do filme, em que o rosto de Nikki/Sue, desfigurado ao estilo dos retratos de Bacon e Freud, é superposto ao rosto do mal, de Phantom.
} 
usa aqui as passagens vídeo-TV-cinema para ficcionalizar um poder maléfico ou benéfico (dependendo do papel do personagem ou grupo), como metáfora da rede de sonhos, espíritos e almas conectadas segundo sua filosofia Transcendental (Lynch, 2007). Não são, portanto, as imagens (amnésicas) do mundo que a mídia televisiva passa todo dia, mas a rede de imagens interiores pressentidas ou imaginadas nos sonhos, lembranças e devaneios, como se formassem parte de um vasto inconsciente coletivo. No fundo, Inland Empire ou O Imperio dos Sonhos é um conto junguiano de Lynch na era digital.

\section{Referências}

Benjamin, W. (1987) "O Narrador" in: Magia e técnica, arte e política. Obras escolhidas Vol. 1, $3^{\underline{a}}$ ed., São Paulo: Brasiliense.

Deleuze, G. (1990) A imagen tempo. Cinema 2. São Paulo: Brasiliense.

Dubois, P. (2004) Cinema, Vídeo, Godard. São Paulo: Cosac Naify.

Freud, S (1980). Obras completas. Ed. Standard Brasileira, Vol. XVII, São Paulo: Imago.

González Requena, J. (2006) Clásico, manierista, postclásico. Repensando la historia del cine americano. Valladolid: Castilla Ed.

Jost, F. (2005) Des vertus heuristiques de l'intermédialité. Intermédialités: histoire et théorie des arts, des lettres et des techniques / Intermediality: History and Theory of Arts, Literature and Technologies, 6, 109-119. Acessado em: http://id.erudit.org/iderudit/1005509ar

Katz, Ch. S. (2008) Um pequeno questionamento (Texto da fala do autor na posse na Academia Brasileira de Filosofia). Acessado em: http://www.freudiana.com.br/documentos/chaimabf.pdf

Lynch D. (2007) Catching the Big Fish. Meditation, Consciousness, and Creativity. Nova York: Penguin.

Morello, D. (2010) David Lynch Inland Empire. Bolonha: Falsopiano Light. 
Müller, J. (2006) Vers l'intermédialité. Histoires, positions et options d'un axe de pertinence. Médiamorphoses, vol. 16, 99-110.

Ortiz de Zárate, A (2011). Relatos emergentes. Inland Empire (2006) de David Lynch. Trama \& Fondo, 31(2), 33-48.

Propp, V. (1984) Morfologia do conto maravilhoso. Rio de Janeiro: Forense-Universitária.

Rajewsky, I. O. (2005). Intermediality, Intertextuality and Remediation: A Literary Perspective on Intermediality. Intermédialités: histoire et théorie des arts, des lettres et des techniques / Intermediality: History and Theory of Arts, Literature and Technologies, 6, 43-64. Acessado em: http://id.erudit.org/iderudit/1005505ar

Todd, A. (2012) Authorship and the Films of David Lynch. Aesthetics Receptions in Contemporary Hollywood. Nova York: I.B. Tauris. 